\title{
To Protect or Not to Protect: Guide for Deciding on Public Release or Intellectual Property Protection of New Plant Cultivars and Germplasm
}

\author{
Mojdeh Bahar and Robert J. Griesbach ${ }^{1}$ \\ Office of Technology Transfer, U.S. Department of Agriculture, Agricultural \\ Research Service, 5601 Sunnyside Avenue, Beltsville, MD 20705-5131
}

Additional index words. plant breeding, variety, plant patent, plant variety protection

\begin{abstract}
The U.S. Department of Agriculture's Agricultural Research Service (ARS) and universities have a long and successful history of developing enhanced germplasm and cultivars that are transferred through public release. Today, nonprotected public release may not be the most appropriate mechanism. Intellectual property (IP) protection as it pertains to the plant germplasm and cultivars is involved and complex. Unlike other scientific areas, in the United States there are three distinct mechanisms to protect plants - namely, utility patents, plant patents, and plant variety protection certificates. Each of these mechanisms offers different criteria for protection and covers different types of plants. This article is a practical tool to help research institutions and scientists decide when to consider releasing a germplasm or cultivar, which factors to consider, who should be involved, and whether IP protection is appropriate.
\end{abstract}

The public sector has a long and successful history of developing enhanced germplasm and finished cultivars that are transferred through public release. For several reasons, such as maintaining genetic integrity, public release may not now be the most appropriate mechanism (Shelton and Tracy, 2017). IP protection of plants is involved and complex (Batur and Dedeurwaerdere, 2014; Clark, 2011). The International Society for Horticultural Science held two symposia on the topic in 2014 and 2018 (Hale et al., 2014). The American Society for Horticultural Science also has held many workshops on the topic. There is still quite a bit of confusion on when and how to protect new plant cultivars (Pardey et al., 2013). In addition, trade secrets and trademarks can also be used to protect new plant cultivars. This article is a practical tool to help research institutions and scientists decide when to consider releasing a germplasm or cultivar, which factors to consider, who should be involved, and whether IP protection-and what type of protection-is appropriate.

Unlike other scientific areas, in the United States there are three distinct mechanisms to protect plants themselves - namely, utility patents, plant patents, and plant variety protection certificates. Each of these mechanisms offers different criteria for protection and covers different types of plants. Cultivars can be protected by a Plant Variety Protection Certificate [PVPC (Chen, 2005)] or a plant patent [PP (Fowler, 2000)]. Asexually

Received for publication 24 Aug. 2018. Accepted for publication 20 Dec. 2018.

${ }^{1}$ Corresponding author. E-mail: robert.griesbach@ ars.usda.gov. propagated plants are covered by plant patents, but sexually propagated crops are covered by PVPCs. An example of a cultivar protected by a PVPC is Capsicum annum L. 'Black Pearl' pepper (Stommel and Griesbach, 2005); an example of a cultivar protected with a PP is Rubus subg. Rubus Watson 'Onyx' (Finn et al., 2011).

Traits, genes, plant parts, and methods of producing or using man-made plant cultivars could be protected through a utility patent. Utility patents can protect both sexually and asexually reproducing plants. An example of a cultivar protected with a utility patent is Capsicum annum L. 'Medusa'. The utility patent (US 7,087,819) covers all nonpungent and ornamental pepper plants that have all the morphologic and physiologic characteristics of Capsicum annuum L. '96P611'. Yet, at times, more than one type of IP protection could be afforded to a single plant species. For example, in addition to utility patent protection, Capsicum annum L. 'Medusa' is also protected with a PVPC (200000140). It is important to note that some mechanisms are more permissive than others. A summary of these three types of protection and their exceptions are presented in Table 1.

Two distinct government agencies are involved in intellectual property in the plant kingdom. Plant Variety Protection applications are examined by the Plant Variety Protection Office (PVPO), Agricultural Marketing Service, U.S. Department of Agriculture, under the authority of the Plant Variety Protection Act of 1970, codified in 7 U.S. Code of Laws (U.S.C.) \$2321 et seq. (U.S. Department of Agriculture, 2013). Plant patent applications are examined at the U.S. Patent and Trademark Office (USPTO), an agency of the Department of Commerce, under the authority of the Plant
Patent Act of 1930, later codified in 35 U.S.C. §161-164 (U.S. Patent and Trademark Office, 2018). Utility Patent applications are examined at the USPTO under the authority found in Art. $1, \S 8, \mathrm{cl} .8$ of the U.S. Constitution and later codified in 35 U.S.C. (U.S. Patent and Trademark Office, 2000).

In addition to these mechanisms, some aspects of plants, such as breeding methods, could be protected as a trade secret, and plant names could be protected under trademark law (Nirwan, 2017). Unlike the three previously mentioned IP protection mechanisms, trade secrets are not time limited. For example, two unique parents, one plant with small purple flowers and the other with large red flowers, when crossed together can result in novel and uniform progeny (i.e., plants with large blue flowers). Progeny of the large blue-flowered plants are not uniform. So, the cross results in plants with large red flowers, small purple flowers, small red flowers, large purple flowers, and so on. In this instance, the original parent plants that produce the desirable progeny can be kept as a trade secret. No one can create the novel plants with large blue flowers without knowing the genetic identity of the parents.

Some institutions may also choose to protect the plant name by registering the name as a trademark, such as Pink Lady ${ }^{\circledR}$ apple, Wave ${ }^{\circledR}$ petunia, Blue Skies ${ }^{\circledR}$ lilac, and Encore ${ }^{\circledR}$ azalea. In many instances, the trademarked plant may also have a conventional cultivar name; for example, Blue Skies ${ }^{\circledR}$ lilac is Syringa vulgaris L. 'Monroe'. It can also be a little more complex. Apples sold as Pink Lady ${ }^{\circledR}$ can be either Malus domestica L. Borkh 'Cripps Pink', 'Rosy Glow', or 'Lady in Red'. Two of the cultivars ('Cripps Pink', PP7880; and 'Lady in Red', PP18787) are also protected through PPs (Luby and Bedford, 2015).

Although any one or combination of PVPC, PP, utility patent, or trade secret can be used to afford plants IP protection, many public institutions, be they governmental or academic entities, may choose to release their new plant cultivars and novel germplasms publicly without IP protection. What follows describes the plant release process used by the U.S. Department of Agriculture's ARS (Plowman, 1993). Although the point of departure is ARS's plant release procedures, the aim is to make the procedures generic so they could also encompass some of the procedures used by our university partners.

Ready or Not: How to Decide Whether a New Cultivar or Enhanced Germplasm Is Ready for Release

It is the primary responsibility of the individual plant breeder to decide whether the potential cultivar or germplasm is ready for release. It is essential that the germplasm or cultivar do the following:

- Represent a useful advance in genetic resources

- Be adequately evaluated

- Offer benefits to users 
- Be new, distinct, uniform, and stable (whether PVPC is sought)

Approval processes for cultivar or germplasm releases are particular to each institution. In some universities, technology transfer offices may play a role in this process. At ARS, after the previously listed criteria have been met, the breeders must discuss their desire to release the germplasm or cultivar with both line and program management.

After there is general agreement to release a new cultivar or enhanced germplasm, the breeder usually drafts a release notice (Supplemental Fig. 1). In addition to the institutional release notice, most breeders also publish their release in one of two scientific, peer-reviewed journals: HortScience for horticultural crops and Journal of Plant Registrations for agronomic crops. In addition, breeders should also register their cultivar, if there is registration authority for that crop, with the International Cultivar Registration Authority (International Society for Horticultural Science, 2018). Many university and all ARS germplasm releases are deposited in the U.S. National Plant Germplasm System (U.S. Department of Agriculture, 2018) to enable further dissemination.

\section{How Is the Name for a New Cultivar or Germplasm Release Selected?}

The International Code of Nomenclature for Algae, Fungi, and Plants (International Association for Plant Taxonomists, 2012) defines a "variety" (abbreviated var.) as a taxonomic rank below that of species and subspecies but above that of form (abbreviated fm.). A "cultivar" is defined by the International Code of Nomenclature for Cultivated Plants (International Society for Horticultural Science. 2009) as an assemblage of plants that 1) has been selected for a particular character or combination of characters; 2) is distinct, uniform, and stable in those characters; and 3) when propagated by appropriate means, retains those characters. For example, the name of a petunia would be Petunia (genus) integrifolia (species) var. integrifolia (variety) fm. alba (form) (Fries) Smith et. Down 'White Glory' (cultivar name). The genus, species, variety, and form are in italics; the cultivar name is in single quotes, without italics.

It is important to note that the botanically defined "variety" should not be confused with the legally defined "variety." Although they both use the same term ("variety"), the designations are not the same. The legally defined "variety" is equivalent to the botanically defined "cultivar."

The Plant Variety Protection Act defines "variety" in $\S 41$ as "a plant grouping within a single botanical taxon of the lowest known rank." The lowest botanical rank is not "variety," but "cultivar." The International Code of Nomenclature for Cultivated plants states in §2.2: "The English words 'variety,' 'form,' and 'strain' or their equivalents in other languages must not be used for 'cultivar.",

In general, germplasm is released under a number; cultivars are given a cultivar name. Cultivar names need to follow the rules of the International Code of Botanical Nomenclature. A trademark search through the USPTO website (www.uspto.gov) should also be conducted to make sure the proposed name has not been trademarked. In case of seed-propagated plants, the PVPO website (http://www.ams.usda.gov/AMSv1.0/pvpo) should also be searched to determine whether the name has been used before for that crop.

\section{Who Is the Breeder/Inventor of a New Cultivar?}

The legal definition of a breeder of a new cultivar is slightly different than the commonly accepted genetic definition. The Plant Variety Protection Act in 7 U.S.C. \$2401 defines a breeder as a "person who directs the final breeding creating a cultivar or who discovers $\&$ develops a cultivar. If the actions are conducted by an agent on behalf of a principal, the principal, rather than the agent, shall be considered the breeder." The statutory language suggests that final breeding means not only the genetic component, but also the selection component of cultivar development.

The Plant Patent Act in 35 U.S.C. $\$ 161$ further defines the inventor (breeder): "If one person discovered or selected (emphasis added) a new and distinct plant, and a second person asexually reproduced the plant and ascertained that the clone(s) of the plant were identical to the original plant in every distinguishing characteristic, the second person would properly be considered a coinventor... However, an inventor may direct that the step of asexual reproduction be performed by a custom propagation service or tissue culture enterprise. Those performing the service would not be considered coinventors, as they are performing these tasks as the agent of the inventor."

\section{Should a New Cultivar Be Protected?}

Although ARS's default position is to release new cultivars and enhanced germplasm lines publicly without IP protection, there are exceptions to this policy. There can be several reasons for protecting new cultivars:

- IP protection better facilitates technology transfer.

- Can allow broader adoption than public release. For example, a cultivar of a new plant/ species not already in the market will not likely get widely accepted by consumers without a marketing campaign. A patentlicense allows a commercial grower to recover the cost of marketing.

- Provides incentive for investments by the private sector in getting the cultivar in the hands of farmers or growers. For example, some vegetatively propagated cultivars 


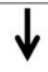

Scientist gets approval to move forward from line and program management

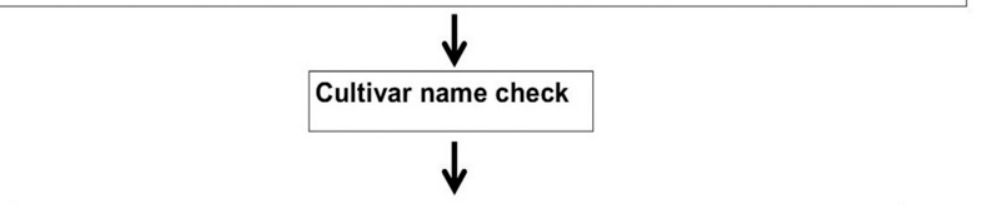

Scientist submits release request to Institutional Review Committee

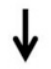

Institutional Review Committee approves release and decides whether protection is needed

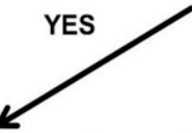

Scientist and patent advisor draft and submit Plant Patent or PVP application

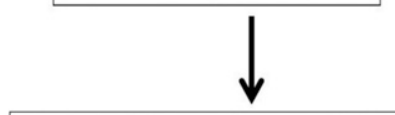

Scientist deposits sample in National Plant Germplasm System (NPGS) or National Center for Genetic Resources Preservation (NCGRP)

Fig. 1. To protect or not to protect: A decision tool for publicly releasing or protecting a new plant cultivar.

can be very susceptible to disease and require a certified disease-free propagation environment. A patent-license allows a commercial grower to recover these added costs.

- IP protection can be used to maintain genetic identity and purity. For example, genetic drift may cause a seed-propagated cultivar to lose a desired trait, such as an onion shape: global vs. high globe. A license with the restriction to use certified seed will guarantee that the desired trait will be expressed in a population at a desired level.

When determining the best mechanism for dissemination of a germplasm or cultivar, the following factors are considered by ARS:

- How is the cultivar different from and/or better than the closest currently available cultivar?

- Would protection likely play a significant role in making the cultivar available to growers and consumers beyond what could be achieved through public release?

- Is protection needed to maintain genetic identify or to ensure the appropriate maintenance of unique traits, such as higholeic acid soybeans? For seed-propagated crops, what class of certified seed is required?
- What is the point of view of key stakeholders-such as commodity groups, growers, university partners, seed companies, and nurseries - regarding protection?

- Is there current commercial interest in marketing and producing the cultivar for sale or a high probability of commercialization in the future?

- Is the potential market for the cultivar of sufficient size to warrant protection?

- Is foreign protection needed?

- If co-owned, what is the co-owner's opinion?

If it is decided that a cultivar should be protected, the next steps vary depending on whether the variety is clonally propagated, clonally propagated cultivars, a plant patent application is filed at the USPTO. For seedor tuber-propagated cultivars, a PVPC application is submitted to the PVPO. It is advisable that breeders become familiar with the PVPC requirements for their specific crop and strive to have all required data collected before presenting a cultivar to the committee for consideration of protection. Because ARS's policy is the free use of its cultivars in further breeding, it has very rarely used utility patent protection for plants. Figure 1 presents a decision tool for whether the plant should be publicly released or protected. seed propagated, or tuber propagated. For
Batur, F. and T. Dedeurwaerdere. 2014. The use of agrobiodiversity for plant improvement and the intellectual property paradigm: Institutional fit and legal tools for mass selection, conventional and molecular plant breeding. Life Sci. Soc. Policy 10(14):1-29.

Chen, J. 2005. The parable of the seeds: Interpreting the Plant Variety Protection Act in furtherance of innovation policy. Notre Dame Law Rev. 81:106-166.

Clark, J.R. 2011. Intellectual property and horticultural science: The path from idea, technology development, commercialization, and impact. HortScience 46:4-5.

Finn, C.E., B.C. Strik, B.M. Yorgey, and R.R. Martin. 2011. 'Onyx' trailing blackberry. HortScience 46:657-659.

Fowler, C. 2000. The Plant Patent Act of 1930: A sociological history of its creation. J. Pat. Trademark Off. Soc. 82(9):621-644.

Hale, C., D. Hunter, W. Roberts, R. Ikin, and S. McMaugh (eds.). 2014. XXIX International Horticultural Congress on Horticulture: Sustaining lives, livelihoods and landscapes (IHC2014): International symposia on innovative plant protection in horticulture, biosecurity, quarantine pests, and market access. Acta Horticulturea Proceeding 1105

International Association for Plant Taxonomists. 2012. International code of nomenclature for algae, fungi, and plants. 19 July $2018 .<$ http:// www.iapt-taxon.org/nomen/main.php/>.

International Society for Horticultural Science. 2009. International code of nomenclature for cultivated plants. 19 July 2018 . <http://www. upov.int/edocs/mdocs/upov/en/caj_66/caj_66_ www_219065.pdf/>.

International Society for Horticultural Science. 2018. International cultivar registration authority. 19 July 2018. <http://www.ishs.org/ nomenclature-and-cultivar-registration/icra/>.

Luby, J.J. and D.S. Bedford. 2015. Cultivars as consumer brands: Trends in protecting and commercializing apple cultivars via intellectual property rights. Crop Sci. 55(6):25042510 .

Nirwan, P. 2017. Trade secrets: The hidden IP right. WIPO Magazine 6:31-34.

Pardey, P.G., B. Koo, J. Drew, J. Horwich, and C. Nottenburg. 2013. The evolving landscape of plant varietal rights in the United States, 1930 2008. Nat. Biotechnol. 31(1):25-29.

Plowman, R.D. 1993. Intellectual property protection of plants: The Agricultural Research Service perspective, p. 33-40. In: Intellectual property rights: Protection of plant materials. CSSA Special Publ. no. 31.

Shelton, A.C. and W.F. Tracy. 2017. Cultivar development in the U.S. public sector. Crop Sci. 57(4):1823-1835.

Stommel, J. and R.J. Griesbach. 2005. Capsicum annuиm L. 'Black Pearl'. HortScience 40:15711573.

U.S. Department of Agriculture. 2013. Plant Variety Protection Act and regulations and rules of practice. 19 July 2018 . <https://www.ams.usda. gov/sites/default/files/media/Plant $\% 20$ Variety $\%$ 20Protection\%20Act.pdf/>.

U.S. Department of Agriculture. 2018. U.S. national plant germplasm system. 19 July 2018 . $<$ https://www.ars-grin.gov/npgs/index.html/>.

U.S. Patent and Trademark Office. 2000. 19 July 2018. <https://www.uspto.gov/sites/default/ files/web/offices/dcom/olia/35amend2.pdf/>.

U.S. Patent and Trademark Office. 2018. 19 July 2018. <https://www.uspto.gov/web/offices/pac/ mpep/mpep-1600.html/>. 


\section{U.S. DEPT. AGRICULTURE}

AGRICULTURAL RESEARCH SERVICE

WASHINGTON, D.C.

AND

THE OREGON AGRICULTURAL EXPERIMENT STATION

CORVALLIS, OREGON

\section{NOTICE TO FRUIT GROWERS AND NURSERY GROWERS OF RELEASE OF THE ORNAMENTAL BLUEBERRY 'PERPETUA'}

The U.S. Department of Agriculture-Agricultural Research Service and the Oregon Agricultural Experiment Station announce the release of an outstanding ornamental blueberry that is believed to be the most strongly repeat flowering blueberry developed from northern adapted germplasm. 'PERPETUA' was selected in Corvallis, OR in 2005 from a population grown from open pollinated seed of CVAC 45 (PI 296412) growing in the USDA-ARS National Clonal Germplasm Repository collection in Corvallis, OR. CVAC 45 was collected from the wild in 1963 in Monmouth, Maine and is listed as Vaccinium corymbosum L. (highbush blueberry) by the USDA- ARS, National Genetic Resources Program, Germplasm Resources Information Network - (GRIN) [Online Database]. When the plant was evaluated in the collection, it was noted for its small fruit size and autumn fruiting. The plant's characteristics for fruit size, leaf shape, and leaf size are intermediate to those of $V$. corymbosum and V. angustifolium Aiton (lowbush blueberry). Since both species are found in the region where the accession was collected, it is presumed to be a hybrid between these two species. 
The commercial highbush blueberry industry was interested in having a cultivar that was small fruited and competitive in the bakery market. Fruit was collected in 2000 from CVAC 45 to try to capture the combination of an upright, medium-sized plant with small fruit. When the population was grown out, a large number of the seedlings had a propensity for producing a second autumnripening crop from flowers that opened in summer. 'PERPETUA' is being released due to its outstanding ornamental characteristics combined with repeat flowering.

'PERPETUA' has been evaluated most extensively at Oregon State University's North Willamette Research and Extension Center (Aurora, OR; OSU-NWREC) and in USDA-ARS plots in Corvallis, OR as well as a test site in Lowell, OR. Plants of 'PERPETUA' are moderately vigorous, small shrubs with attractive, extremely dark green, glossy leaves borne on fairly upright shoots. The plant has not shown any susceptibility to foliar diseases such as leaf rust (Pucciniastrum vaccinii [G.

Wint.] Jørst).

Early in the spring, the floral buds break, flower and set fruit. The flowers are white and have a typical shape for blueberry. In controlled crosses, flowers set a comparable number of fruit regardless of whether self-pollinated or pollinated with a bulk pollen sample. The fruit ripen fairly early in mid-June in most years. The vegetative buds break soon after flowering and grow for a few weeks before the first black tip stage. Flower buds form and instead of remaining dormant, break resulting in a second flowering period that begins in early July. The second crop ripens from early September through the cooler and shorter days of September and October. Production of ripe fruit only stops once freezing temperatures begin, as late as 2 November in 2011 at the test sites. 
The fruit are small $(1.2 \mathrm{~g})$ and most similar to that of $V$. angustifolium. They are attractive with a uniformly round shape, an attractive calyx, and a nice medium blue color. The fruit of 'PERPETUA' are fairly soft, have a mild flavor and a wet picking scar making them poorly suited for the commercial fruit market but fine for a home garden market. The fruit are borne in tight clusters and the combination of blue and green fruit with the dark green foliage is particularly attractive in late summer. The plants have a good balance between fruit production and vegetative growth. While the potential yield of a fully mature plant is unknown, the plants produced about $1.1 \mathrm{~kg}$ two years after planting.

'PERPETUA' is introduced as an attractive ornamental blueberry with repeat flowering and fruiting. 'PERPETUA' should be adapted to typical soil environments where blueberries and other Ericaceous plants can be grown. The ultimate cold hardiness and heat tolerance of 'PERPETUA' is not known, though based on the maternal parent it is expected to have good winter hardiness.

'PERPETUA' should also be useful to breeding programs looking for sources of repeat flowering for low chill environments that are different than southern highbush blueberry.

'PERPETUA' nuclear stock has tested negative for Blueberry shock, Blueberry shoestring, Blueberry scorch, Blueberry leaf mottle, Peach rosette mosaic, Tomato ringspot, and Tobacco ringspot viruses.

'PERPETUA' is patent pending. Further information on licensing for propagation or a list of nurseries propagating 'PERPETUA' is available from the USDA-ARS, Office of Technology Transfer, Licensing Section, 5601 Sunnyside Avenue, Room 4-1159, Beltsville, MD 20705-5131 (email: license@ars.usda.gov). The USDA-ARS does not sell plants. 
ARS GIVES NO WARRANTIES OR GUARANTEES, EXPRESSED OR IMPLIED, FOR THE

MATERIAL, INCLUDING MERCHANTABILITY OR FITNESS FOR A PARTICULAR

PURPOSE.

Director, Oregon Agricultural Experiment Station

Date

Administrator, Agricultural Research Service

Date

U.S. Department of Agriculture 